She was conditioned for an allogenic HLA identical bone marrow transplant from a sister, with fractionated total body irradiation $(12 \mathrm{~Gy})$ and cyclophosphamide $(60 \mathrm{mg} / \mathrm{kg}$ body weight $\times 2$ ); as prophylaxis for graftversus-host disease, she received cyclosporin A $(1.5 \mathrm{mg} / \mathrm{kg}$ body weight every $12 \mathrm{~h}$, starting on day -1) and a short course of methotrexate, according to the Seattle protocol.

On the day of the bone marrow infusion, she developed fever and was put on broadspectrum antibiotics and a regimen with amphotericin B, was added later. Her microbiological study and chest X-ray were normal. She had, meanwhile, progressive weight gain, abnormal liver function test (increased of bilirubin and $\gamma$ glutamyl transaminase) and deterioration of renal function. By day +10 she had ascites, tender hepatomegaly and oedemas of her lower limbs, all suggestive of hepatic veno-occlusive disease. A thoracoabdominal computed tomography (CT) scan was carried out which showed hepatosplenomegaly, ascites and retroperitoneal lymphadenopathy. Soon after the transplant she developed severe mucositis.

On day +13 she was dyspnoeic and a chest $\mathrm{X}$-ray showed consolidation in the lower left lobe, left pleural effusion and a poorly defined nodule in the upper right lobe. Two days later, the nodule enlarged and consolidation at the base of both lungs with bilateral pleural effusion were observed. Because of the suspicion of pulmonary aspergillosis, the dose of amphotericin B was increased.

On day +20 , neutrophil engraftment was detected (neutrophil count $>0.5 \times 10^{9} / 1$ ). On day +22 , the patient presented respiratory distress syndrome and was transferred to the Intensive Care Unit, where she eventually required mechanical ventilation, and died six days later $($ day +30$)$.

Necropsy showed right pulmonary aspergillosis, radiation pneumonitis with severe diffuse alveolar damage, hepatomegaly with severe cholestasis and venous wall oedema, visceral congestion, and intense generalised mucositis.

The role that the precedent of toxic oil syndrome played in the post-transplant course of this patient is a matter of speculation.

P LLAMAS-SILLERO MI GÓMEZ-RONCERO R FORÉS

R CABRERA

JL DIEZ

MN FERNÁNDEZ

Department of Hematology, Clinica Puerta de

Hierro, Universidad Autonoma de Madrid, San Martin de Porres 4, 28035 Madrid,

Spain

1 Tabuenca JM. Toxic allergic syndrome caused by ingestion of rapeseed oil denatured with aniline. Lancet 1981; ii: 567-8.

2 Martinez-Tello FJ, Navas-Palacios JJ, Ricoy $\mathrm{JR}$, et al. Pathology of a new toxic syndrome caused by ingestion of adulterated oil in Spain. Virchows Arch / A / 1982; 397: 261-85.

3 Phelps RG, Fleischmayer R. Clinical, pathologic and immunopathologic manifestations of the toxic oil syndrome. Analysis of fourteen cases. $\mathcal{F}$ Am Acad Dermatol 1988; 18: 313-24.

4 Alonso-Ruiz A, Calabozo M, Pérez-Ruiz F, Mancebo L. Toxic oil syndrome. A long-term follow-up of a cohort of 332 patients. Medicine 1993; 72: 285-95.

\section{Criteria for the diagnosis of} toxic oil syndrome

1 intake of cooking oil sold in bulk, and/or other cases among relatives

2 interstitial-alveolar pattern on chest $\mathrm{X}$-rays during the first 4 months

3 esoinophilia $(>500$ eosinophils $/ \mu \mathrm{l})$, myalgia, or rash during the first 4 months

4 pulmonary hypertension, hepatic disease, scleroderma, sicca syndrome, polyneuropathy, joint contractures, Raynaud disease, muscle cramps, chronic lung disease

For diagnosis, either

- at least two of criteria 1, 2, or 3 or

- at least criteria 1,2 , or 3 , and two or more of the features included in criterion 4 should be fulfilled

\section{Proptosis, skull infarction and epidural haematoma in sickle thalassemia}

Sir,

Infarction of the long bones is a common complication of sickle cell disease. However, there are less than 10 cases of orbital bone infarction associated with sickle cell disease in the English literature. ${ }^{1}$ A combination of orbital and skull bone infarction with associated epidural haematoma in sickle cell disease has been reported only once in the world literature, ${ }^{2}$ with our case being the second. This case is unique in that it is sickle thalassemia and hence occurred at a later age.

A 35-year-old man, admitted with painful limitation of eye movements and proptosis of the left eye of eight days duration, had absent extraocular movements in all fields of gaze with the cornea, sclera, fundus, pupils and visual acuity being normal. The patient had a haemoglobin of $8.1 \mathrm{~g} / \mathrm{dl}$ and sickle cells on a peripheral smear. Sickling test was positive and haemoglobin electrophoresis revealed $\mathrm{Hb} \mathrm{S}-48.8 \%, \mathrm{Hb} \mathrm{F}-49.0 \%$ and $\mathrm{Hb} \mathrm{A} 2-$ $2.2 \%$, consistent with a diagnosis of sickle thalassemia. A bone marrow biopsy depicted areas of infarction. The left orbital ultrasonography demonstrated a mass with soft tissue echotexture in the upper temporal quadrant of the left eye, displacing the eye ball inferomedially. A computed tomography (CT) scan of the orbit showed a nonenhancing soft tissue mass without any adjacent bone erosion, destruction or intracranial extension (figure). CT scan of the brain showed an epidural haematoma. A bone scan using $740 \mathrm{Mbq}$ of $99 \mathrm{mTc}$ MDP (methylene diphosphonate), showed abnormal uptake in the skull bones and bone marrow imaging using $370 \mathrm{Mbq}$ of $99 \mathrm{mTc}$ colloidal sulphur, done two days after the bone scan showed multiple cold areas in the skull. These radiological findings are suggestive of periorbital and skull bone infarction and adjacent haematoma and swelling secondary to it. The patient received hydroxyurea, blood transfusion and analgesics. After 14 days he regained full movements of the eye and proptosis disappeared.

Sickle cell disease is rarely associated with periorbital and skull bone infarctions.

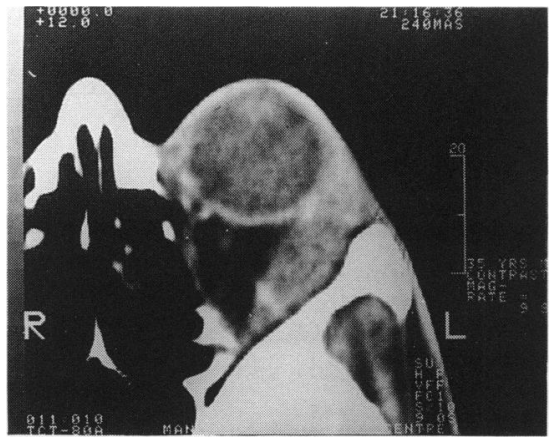

Figure CT scan of the left orbit showing non-enhancing soft tissue mass

\begin{tabular}{|l|}
\hline Periorbital swelling: causes \\
\hline - trauma \\
- infarction \\
- exophthalmic goitre \\
- nephritis \\
- lacrimal gland involvement \\
- glaucoma \\
- bleeding due to blood dyscrasias \\
- leukaemic infiltration \\
- metastatic neuroblastoma \\
- cavernous sinus thrombosis \\
\hline
\end{tabular}

Though intracranial bleeding occurs in sickle cell disease, a combination of epidural haematoma and periorbital and skull infarction has only been reported once before. ${ }^{2}$

One should include periorbital bone infarction due to sickle cell disease in the differential diagnosis of periorbital swelling. ${ }^{3}$ It is often difficult to differentiate bone infarction from osteomyelitis and a $99 \mathrm{mTc}$ MDP bone scintigraphy is useful in demonstrating activity-deficient areas in infarction and hyperactive areas in osteomyelitis. This is important as both can coexist in sickle cell disease and clinical differentiation is often difficult. ${ }^{3}$ The combined use of an orbital CT scan and orbital ultrasonogram are useful in differentiating the various orbital problems in such cases. ${ }^{4}$

JACOB TONY GAYATHRI SUBRAMANYA KG KALLUR AV CHALAPATHY SHUBA SHESHADRI BHUSHAN LAKHKAR Kasturba Medical College, Manipal 576 119, Karnataka, India

Correspondence to Dr JC Tony, Department of Medicine, Kasturba Medical College, Manipal 576 119 , Karnataka, India

1 James DS, Richard EW, William CS, et al. Orbital complications of sickle cell disease. Int $\mathcal{f}$ Pediatr Otorhinolaryngol 1990; 19: 181-4.

2 Ahmad AM, Mark Y, Jahed H, et al. Proptosis skull infarction, and retroorbital and epidural hematomas in a child with sickle cell disease. Clin Pediatr 1987; 26: 536-8.

3 Itzhak G, Ariel K, Hanna G. Frontal and orbital bone infarctions causing periorbital swelling in bone infarctions causing periorbital swelling in patients with sickle cell
mol 1984; 102: $1486-8$.

4 John PB, Frances MG. Orbital infarctions in John PB, Frances MG. Orbital infarctions in
sickle cell disease. Pediatrics 1981; 67: 879-80. 